\title{
Comparative Study on the Sustainable Livelihood of Ethnic Tourism Villages in China From the Governance Model Perspective
}

\author{
Shang Qianlang*, Wang Huanhuan, Li Mengxue \\ Tourism and Cultural Industry Research Institute, Yunnan University of Finance and Economics, Kunming, Yunnan, \\ China \\ *Corresponding Author. Email: zz1732@ynufe.edu.cn
}

\begin{abstract}
The China tourism development in ethnic villages has promoted the transition of family livelihood models to tourism business activities, and different governance models at destinations have different impacts on livelihood transformation, which has raised concerns about how to achieve sustainable livelihood issues. From the perspective of governance model, this research focuses on the two models of "Government-oriented" and "Enterprise-oriented" in the development of ethnic village tourism, compares the outcomes of sustainable livelihoods under different governance models based on two ethnic villages cases. The paper explained the specific process of governance modes acting on livelihood changes, refined the internal impact of governance models on sustainable livelihoods, and to further understand the relationship between tourism development and sustainable livelihoods. The research results show that: Firstly, from the results of the sustainable livelihood analysis of the cases, the performance of the Jinglai 'Enterprise-oriented' governance model is better than the Hansha 'Government-oriented'. Secondly, different elements arrangement of the tourism governance models could result in different sustainable livelihood outcomes. Thirdly, the governance models influence livelihood sustainable outcomes through internal mechanisms such as market economic effects, government policy support, and land use patterns.
\end{abstract}

Keywords: Ethnic Tourism Villages, Sustainable Livelihood, Livelihood Capitals, Livelihood Outcomes, Governance Model

\section{INTRODUCTION}

Tourism in ethnic villages has become a significant pathway of poverty alleviation and rural vitalization in numerous ethnic regions in China. For the past few years, abundant of social capital was invested into ethnic villages to develop tourism under the auspices of a government initiative, which has generated various governance models in ethnic villages' tourism. Family livelihood patterns are now closely associated with tourism development since the booming in tourism has not only changed the overall social-economic structure, but also motivated the transformation of livelihood pattern from agriculture-dependent to tourism-dependent in ethnic villages ${ }^{[1][2][3]}$. Therefore, it is the most concern that promoting coordination among ecological protection, residents' livelihoods and cultural inheritance during the quick expanding of ethnic tourism.
Owing to the imparity in economic foundation and development environment, ethnic region adopted multiple management models, showing diverse characteristics in governance system, collaborative models, profit distribution, community engagement and other aspects. It also may cause unlike outcome of sustainable livelihood. Then, how do diverse governance models affect sustainable livelihood differently? Based on the perspective of management model, and by comparing enterprises-dominate model with government-led model in different ethnic villages in the most southwestern China, this study will analysis concrete reflection of these two management models, then summarize the impact of sustainable livelihood given by management models. 


\section{LITERATURE REVIEW ON SUSTAINABLE LIVELIHOOD AND TOURISM}

Livelihood is the pathway of earning a living. Sustainable livelihood means being able to recover from shocks and provide livelihood opportunities for offspring. Sustainable livelihood has attracted extensive attention and turned into a mainstream worldwide in recent years ${ }^{[4]}$. Sustainable livelihood originated in the west when scholars investigated poverty alleviation of farmers. After that, it gradually formed a set of normative theoretical system and analytical paradigm. International organizations and agencies have proposed the analyzing framework of sustainable livelihood approach (SLA), and developed into practical working methods ${ }^{[5]}$.

Scholars have applied the sustainable livelihood theory into tourism research ${ }^{[2]}$, and formed a normative research paradigm ${ }^{[6]}$. Tourism has the effect of "poverty reduction", and the theoretical relationship between tourism and poverty alleviation has undergone the development process of liberalism, neoliberalism, critical stage, alternative development and post-development ${ }^{[7]}$. "Sustainable tourism" has its deficiency both conceptually and practically, while sustainable livelihood offers a more holistic perspective of tourism development and how to eliminate poverty ${ }^{[8]}$. New family livelihood patterns adapted to the development of tourism have emerged, and produced the cultural adaptation under the livelihood transformation ${ }^{[4]}$.

The importance of governance model in sustainable livelihood has been noticed, and scholars began to analyze tourism development and sustainable livelihood from the perspective of management model. It has been founded that adopting different management models in tourism development has different effects on raising farmers' livelihood capital ${ }^{[9]}$. Governance model is related to the community and residents' engagement in tourism. It is believed that different governance modes will have different influences on residents' livelihood and tourism effect ${ }^{[10][11]}$. Existing studies have explored the relationship between tourism development and livelihood, but they considered tourism environment, culture, and community insufficiently. The foundation of sustainable livelihood theory construction in tourism is relatively weak, and the internal mechanism how governance model affects livelihood has not been revealed in these few studies ${ }^{[12]}$. Therefore, this paper will make a comparative evaluation on sustainable livelihood results under different governance models based on cases analysis. Then, it will further analyze interactions among governance models elements, and internal impacts of governance models on sustainable livelihood.

\section{RESEARCH METHODS}

\subsection{Study Area}

Two Dai ethnic villages in Yunnan province were considered as cases, which represented two typical governance models, "Enterprise-oriented" and "Government-oriented" models. The first village is Jinglai in Xishuangbanna, and the other one is Hansha in Dehong. Readers can get deeper understanding of different governance models by comparing these two cases.

\subsection{1. "Village+ Enterprises + Residents" model in Jinglai}

Jinglai is affiliated to Daluo Village Committee in Xishuangbanna Dai Autonomous Prefecture, Yunnan Province. It was selected in the second batch of Traditional Chinese Villages list in 2013, and tourism Villages with Ethnic characteristics in Yunnan Province in 2015. In 2018, it was included in National 4A Tourist Attractions. Jinglai established "Enterprise-oriented" development model depending on the management experience that tourism group had on scenic area management and project developing, and advocated "culture protection, inheritance and sustainable development" in development, taking the business model "Village + Enterprises + Residents" led by enterprises, participated by residents, setting up village regulations, rights and obligations of scenic spots, companies and residents. They also established "the scenic area management committee" to build common management and communication mechanism, eventually formed the governance mode including both enterprise management and traditional culture characteristics.

\subsection{2. "Government + Enterprises + Residents" model in Hansha}

Hansha is affiliated to Jiedong village committee in Dehong Dai and Jingpo Autonomous Prefecture, Yunnan province. In 2008, It was listed as a characteristic village of Rural tourism in Yunnan province, and then, it was both listed as Traditional Village in China and National 3A Tourist Attraction in 2014. Government played a leading role in the process of tourism development and Ruili Municipal Government set up the "Hansha Project Leading Group" to promote the construction of the project in 2013, and introduced development corporations as main part, establishing the business model of "Government + Enterprises + Residents".

\subsection{Data sources and analyzing methods}

The data in this paper was mainly obtained by means of stakeholders' interviews, household surveys, participatory observation, and others. And semi- 
structured interviews and collective interviews were primary ways taken in interviews. The author has conducted preliminary, formal, and tracking investigations in villages in March 2018, July 2018, and May 2019 respectively. The total number of stakeholders and insiders in the interviews was 52 (28 people in Hansha;24 people in Jinglai), and each interview lasted about one to two hours.

The questionnaire in this study consisted of 5 parts and 23 types of questions according to the household livelihood capitals, livelihood strategies and livelihood outcomes involved in the sustainable livelihood analytical framework. Ethnic villages in this study included Hansha (325 households, N1=325) and Jinglai (112 households, $\mathrm{N} 2=112$ ), with a total of 437 households $(\mathrm{N}=\mathrm{N} 1+\mathrm{N} 2=437)$, and the number of samples (S) were about205 ( $\mathrm{N}=440, \mathrm{~S}=205)$. There were 210 valid questionaries ( $48 \%$ of $\mathrm{N}$ ) during the whole survey, among which 156 samples ( $48 \%$ of N1) were obtained in Hansha and 54 samples (48\% of N2) were obtained in Jinglai. The data were measured by Likert Scale, and the average rating score between 1 and 2.4 indicated agreement, between 2.5 and 3.4 indicated neutrality, and between 3.5 and 5 indicated disagreement.

Considering the construction and measurement of index, the computational formula of livelihood capital is:

$$
C_{i}=\sum_{j=1}^{m} W_{j} X_{S_{i j}}
$$

In the formula (1), $C_{i}$ represents the value of livelihood capital of sample $\mathrm{i} ; W_{j}$ represents the weight of $\mathrm{j} ; X_{S_{i j}}$ is the standardized value of sample $\mathrm{i}$ under index $\mathrm{j} ; \mathrm{m}$ is the index number.

Standardized value is nondimensionalized by range standardization, and the formula is:

$$
X_{S_{i j}}=\left(X_{i j}-X_{j_{\min }}\right) /\left(X_{j_{\max }}-X_{j_{\min }}\right)
$$

In the formula (2), $X_{S_{i j}}$ represents the standardized value of sample $\mathrm{i}$ with index $\mathrm{j} ; X_{i j}$ is the value of sample $\mathrm{i}$ with index $\mathrm{j} ; X_{j_{\max }}$ is the maximum of index $\mathrm{j}$, and $X_{j_{\min }}$ is the minimum of index $\mathrm{j}$

In formula (1), by means of principal component analysis, the weight formula is:

$$
W_{P C A}=\frac{M}{N}
$$

In the formula (3), $\mathrm{M}$ is the scoring coefficient of main factors, $\mathrm{N}$ is the characteristic root; the index weight is determined according to all capital types, and $W_{P C A}$ needs to be normalized to obtain the corresponding index weight.

\section{RESEARCH RESULTS}

\subsection{Evaluation of livelihood capital of ethnic tourism villages under different governance models}

According to Figure 1, the average household livelihood capital of Jinglai is 0.599 , which is higher than that in Hansha of 0.442 . Jinglai performed better than Hansha in six livelihood capital items by comparing each sub-capital. Among them, there was the biggest difference in cultural capital (Jinglai, 0.072; Hansha, $0.009)$, and significant differences in human capital $(0.132 ; 0.095)$, natural capital $(0.064 ; 0.044)$ and physical capital $(0.110 ; 0.044)$. While there were minimal differences in financial capital $(0.044 ; 0.035)$ and social capital $(0.178 ; 0.175)$.

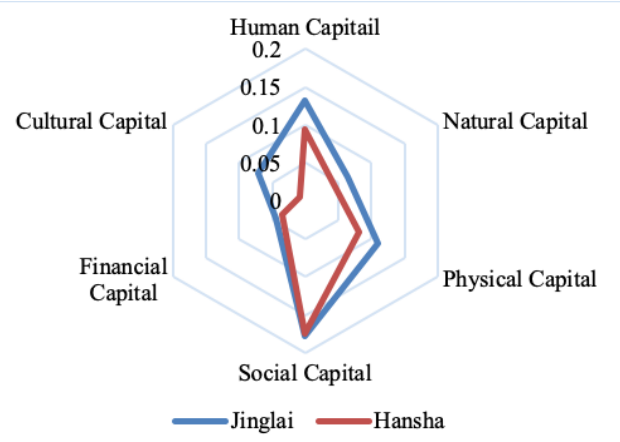

Figure 1 Jinglai and Hansha Village Livelihood Capital Assessment

\subsection{Evaluation of sustainable livelihood of ethnic tourism villages under different governance models}

\subsection{1. economic sustainability}

Most residents in Jinglai believe that tourism development has changed the family lifestyle (average $=$ 1.83), and made the livelihood activities more multivariate (average $=1.76$ ), besides, it has brought ascension in both family income (average $=1.69$ ) and welfare $($ average $=1.69$ ), and residents believed that tourism development cannot make their income fluctuate too much (average $=2.26$ ). While most residents in Hansha were not satisfied with the economic income growth brought by the tourism development (average $=3.15$ )

\subsubsection{Social sustainability}

The sustainable social development of Jinglai has been recognized by most residents. During the tourism development, better communication has been maintained between tourism companies and residents, besides, the establishment of "cooperation agreements" and "Village regulations and agreements" also laid the institutional 
foundation for bilateral cooperation. The social contradictions in Hansha are mainly reflected in the following aspects: First, there is a lack of communication between residents and tourism companies. Second, there is a certain distrust between residents and their cadres.

\subsection{3. environment sustainability}

With the development of tourism and the government's emphasis on the protection of traditional villages, the ecological environment protection in Jinglai has been greatly improved in recent years while there was no waterpipes, sewage pipes and treatment facilities before. Since Hansha scenic area is at the initial stage of development, the company has improved and beautified the overall environment of the village, strengthened the management of environmental hygiene of the scenic spot, and also worked with the village committee to promote environmental protection among residents after it was put into operation.

\subsection{The impact of tourism governance model on sustainable livelihood}

Combined with specific characteristics of the tourism governance model in the two cases, the paper analyzes the impact on the local sustainable livelihood from five factors, including the development concept and theme positioning, operation model, governance system arrangement, profit distribution model and tourism and cultural product development.

\subsubsection{The concept of tourism development affects residents' recognition of tourism}

From the perspective of development effect, the brand effect of "the famous traditional ethnic village on China- Myanmar border" has become prominent, and "border tourism" and "traditional ethnic culture" have formed the main support for tourism in Jinglai. It's concept of development reflects the local resource characteristics and marketing environment, and residents have a deep recognition of tourism development, which drives residents' livelihood activities to tourism development indirectly.

Due to the short tourism development time, the brand effect of "The first Village of Dai customs in Ruili" has not yet appeared, and there are serious similarities with the scenic spot "one village and two countries". The predicament in Hansha has directly affected the residents' recognition of the tourism development.

\subsubsection{Business model guides tourism livelihood activities through the role of stakeholders}

First, the government's role in tourism management will have an important impact on the process of livelihood changes. The tourism development of Jinglai highlights the relationship between villages, enterprises and residents, while government dominates the whole process of tourism development in Hansha.

Second, the way and role of communities' and residents' engagement in tourism development will affect the degree of livelihood changes. It puts the communities and residents in a prominent position, and residents can participate in the development of tourism through scenic work, tourism management and other ways in Jinglai. The role of community in tourism development has been "ignored", which means there is no direct participation and voice in the decision-making of tourism and development.

\subsubsection{Consummate the governance system to ensure the participation of residents and ways to} achieve it.

First, the perfect governance system can create a fair operating environment for residents, and produce a variety of tourism livelihood activities. The governance system in Jinglai scenic spot is perfect, providing fair and reasonable employment opportunities and business environment for residents, and enriching family livelihood activities. While Hansha does not have a perfect governance system in tourism development.

Second, the combination of modern governance system and local culture ensures the way of community participation and promotes the change of livelihood. The establishment of "village rules and regulations" and "scenic area management Committee" in Jinglai reflects the management idea of integrating the governance system and local culture in the scenic area, which ensures the way for the community to participate in the development of tourism and promotes the change of local livelihood.

\subsubsection{The model of interest distribution drives the livelihood change through economic incentives}

First, the profit distribution model drives the transfer of local livelihood activities to tourism development through the incentive role. Jinglai's "ticket sharing" directly links the company and village collective income with the volume of travelers, which makes the community more confident and determined to take the road of tourism development, and drives the development of family tourism livelihood activities. The distribution model of "shop operating profit sharing" in Hansha is not conducive to the "centripetal force" of tourism development jointly formed by company, village and residents.

Second, land leasing income in tourism development of ethnic villages affects livelihood activities. During the 
development of tourism in Jinglai, a large number of collective and residents' land has been rented, which enriches the livelihood activities of residents through working in scenic spot and participating tourism business. While the residents in Hansha have fewer opportunities to work in scenic area.

\subsubsection{Development of tourist products provide residents with business content and space}

First, from the perspective of external environment, the adaptation degree of tourism product development to macro-policy and tourism market changes will affect the attraction level of scenic spots then change local livelihood. Jinglai scenic spot is designed for self-driving journey, honeymoon tour, recreational tour and other new ways, and it mainly focus on resort hotels, self-driving camping and other aspects on later development.

Second, from the perspective of internal management, the development of two different tourism products, "differentiated operation" and "homogenized tourism shopping", will affect tourism income and the choice of livelihood activities. The tourism products sold by Jinglai scenic area companies and residents are different even the types of tourists too. But the "homogenization" phenomenon occurs within interior management of company and residents, which is easy to form internal competition.

To sum up, tourism governance model has direct or indirect influence on local livelihood changes. Livelihood activities also show different characteristics through different combinations and arrangements of governance elements.

\section{CONCLUSION}

From the perspective of sustainable livelihood evaluation of different governance models, the "village + enterprise + household" model led by enterprise and participated by community and residents in Jinglai has a better performance in livelihood capital and livelihood outcome than the "Government + Enterprises + Residents" model led by the government in Hansha. The village regulations and the governance committee of scenic spots provide institutional guarantee for residents to participate in tourism development, and the profit distribution model enhances residents' enthusiasm to participate in. Besides, the formulation of village regulations combines modern governance system with local culture to guarantee the way of community participation.

From the aspect that how elements arrangement of tourism management affect the result of sustainable livelihoods: governance model directly or indirectly affects the degree of the community and residents' participation in tourism development, management standardization in scenic area, residents identity and others, through the concept of tourism development and theme orientation, business model, governance system, profit distribution, tourism product development strategy, and many other aspects which engender different sustainable livelihood outcomes .

The main contributions of this study are as follows: First, it provides theoretical reference and lesson for the selection of tourism governance model and the realization of sustainable development in ethnic villages. This paper evaluates different sustainable livelihood under different governance models, and constructs the mechanism that how governance models affects sustainable development of livelihood. The sustainable livelihood theory can provide theoretical reference and lesson for tourism governance models and sustainable development in ethnic village tourism. Second, it puts forward discourse practice, cases references, countermeasures, and suggestions to realize sustainable livelihood of communities and families in the development process of ethnic village tourism. This study surveys the choices of tourism governance models from the perspective of sustainable livelihood, highlighting the livelihood rights of communities and families in the development process of tourism in ethnic villages, and relevant cases can give cases references and countermeasures to achieve sustainable livelihood.

\section{ACKNOWLEDGMENTS}

This research was supported by the National Natural Science Foundation of China "Study on the Family Livelihood Resilience of Ethnic Tourism Villages along the China-Myanmar Border: Multidimensional Measurements, Evolutionary Mechanisms and Cooperative Governance" (72064039) and the Humanities and Social Sciences Research Project in 2020 of the Ministry of Education of China "Research on the Classification Evaluation and Realization Path of Family Sustainable Livelihood in Border Ethnic Tourism Villages from the Perspective of Local Knowledge" (20YJC630118).

\section{REFERENCES}

[1] Mbaiwa, J. E. (2011) Changes on traditional livelihood activities and lifestyles caused by tourism development in the Okavango Delta, Botswana. Tourism management, 32(5), 1050-1060.

[2] Shen, F., Hughey, K. F., Simmons, D. G. (2008) Connecting the sustainable livelihoods approach and tourism: A review of the literature. Journal of Hospitality and Tourism Management, 15(1), 19-31.

[3] Wang, X., Xi, J. (2015) Study on Livelihood Transition of Local Residents in the Tourist Resort 
Area of Jinshitan. Dalian. Resour. Sci, 37, 24042413.

[4] Liu, X. J., Sun, J. X. (2019) Traditional cultural adaptation of residents in an ethnic tourism community: Based on personal construction theory. Tourism Tribune, 34(2), 16-28.

[5] Nyaupane, G. P., Poudel, S. (2011) Linkages among biodiversity, livelihood, and tourism. Annals of tourism research, 38(4), 1344-1366.

[6] Simpson, M. C. (2009) An integrated approach to assess the impacts of tourism on community development and sustainable livelihoods. Community development journal, 44(2), 186-208.

[7] Scheyvens, R. (2012) Tourism and poverty. Vol. 23. Routledge.

[8] Tao, T. C., Wall, G. (2009) Tourism as a sustainable livelihood strategy. Tourism management, 30(1), 90-98.

[9] Qian, C., Sasaki, N., Jourdain, D., Kim, S. M., Shivakoti, P. G. (2017) Local livelihood under different governances of tourism development in China-A case study of Huangshan mountain area. Tourism Management, 61, 221-233.

[10] Chen, H., Zhu, T., Krott, M., Maddox, D. (2013) Community forestry management and livelihood development in northwest China: integration of governance, project design, and community participation. Regional Environmental Change, 13(1), 67-75.

[11] CHEN, J., Zhang, L. Q., Yang, X. J., Li, G. (2017) The impact of tourism development on changes of households' livelihood and community tourism effect: A case study based on the perspective of tourism development mode. Geogr. Res, 36, 17091724.

[12] Xueyan, Z. (2017) Sustainable livelihoods research from the perspective of geography: The present status, questions and priority areas. Geographical Research, 36(10), 1859-1872. 